\title{
Advances in Plastic Forming of Metals
}

\author{
Myoung-Gyu Lee ${ }^{1, *}$ (iD) and Yannis P. Korkolis ${ }^{2, * \text { (i) }}$ \\ 1 Department of Materials Science and Engineering, Seoul National University, Seoul 08826, Korea \\ 2 Department of Mechanical Engineering, University of New Hampshire, Durham, NH 03824, USA \\ * Correspondence: myounglee@snu.ac.kr (M.-G.L.); Yannis.Korkolis@unh.edu (Y.P.K.); \\ Tel.: +82-2-880-1711 (M.-G.L.); +1-603-862-2772 (Y.P.K.)
}

Received: 3 April 2018; Accepted: 6 April 2018; Published: 16 April 2018

\section{Introduction}

Forming of metals through plastic deformation is a family of methods that produce components through re-shaping of input stock, oftentimes with little waste. Therefore, forming is one of the most efficient and economical manufacturing process families available. A myriad of forming processes exist in this family. In conjunction with their countless existing successful applications and their relatively low energy requirements, these processes are an indispensable part of our future. However, despite the vast accumulated know-how, research challenges remain, be they related to forming of new materials (e.g., for transportation lightweighting applications), pushing the envelope of what is doable, reducing the intermediate steps and/or the scrap, or further enhancing the environmental friendliness. The purpose of this Special Issue is to collect expert views and contributions on the current state-of-the-art on plastic forming, and in this way to highlight contemporary challenges and to offer ideas and solutions were possible.

\section{Contributions}

Our thought at the onset of this effort was to attract contributions to enhance the understanding of metal deformation processes; discuss improved material models available for simulating forming; improve the traditional and lightweight metal forming processes and modeling capability; and promote research on forming of new materials and/or new forming technologies at various length scales, from microscale to macroscale. The contributions we received can be classified under two major categories: bulk forming and sheet/tube forming.

\subsection{Bulk Metal Forming}

The papers on bulk forming fall under two themes: processing studies and material characterization and modeling.

Du et al. [1] use finite element analysis to simulate hydrostatic extrusion under pressure- and displacement-control. They use these models to examine the relationships between extrusion pressure, extrusion ratio, and die cone angle. Amigo and Camacho [2] use finite element analysis to study the central-burst defect in extrusion of DP800 steels. They use the modeling tool to design multiple-pass dies as an alternative to single-pass extrusions which would be prone to central-burst. Behrens et al. [3] numerically examine the formation of an oxide scale during hot forging of steel and it effect on material flow and frictional conditions. Alexandrov et al. [4] examine the formation of a severely-deformed layer near the surface due to friction-induced shearing. They propose a new criterion for determining the boundary between the layer of severe plastic deformation and the bulk of the material.

Shifting now to material characterization and modeling, Shun et al. [5] use an artificial neural network to model the hot deformation behavior of an Al-Si-Mg alloy with an Arrhenius-type constitutive model. Zhou et al. [6] identify the optimum hot-working parameters of an as-cast 
$30 \mathrm{Cr} 2 \mathrm{Ni4MoV}$ steel at high temperatures and intermediate strain rates using processing maps. Zhang and Jiang [7] use electron back-scatter diffraction to understand the grain refinement during equal-channel angular extrusion (ECAE) of a NiTiFe shape-memory alloy. Salcedo et al. [8] investigate the production and properties of ultrafine-grained cams from AA5083 by isothermal forging of a billet that first underwent an ECAE process. Zhao et al. [9] examine magnesium metal matrix composites, where the $\mathrm{Mg}$ matrix is reinforced by silicon carbide particles (SiCp). In their work, they assess the influence of different sizes and percentages of SiCp particles on microstructural evolution during deformation, as well as on strength, ductility and formability. Li et al. [10] discuss the ultra-low cycle fatigue (e.g., as in an earthquake) of an X65 steel pipeline using experiments and finite element models. A range of material models are used in these simulations, and the material characterization experiments are supplemented by texture-based multiscale simulations, e.g., for calibrating the anisotropic yield locus.

\subsection{Sheet/Tube Metal Forming}

The papers in this category are mainly discussing process limits and defects. Morales-Palma et al. [11] discuss the extension of the maximum force principle to predict localized necking in stretch-bending. Chalal and Abed-Meraim [12] examine the open question of necking prediction by considering three numerical necking criteria. These are used to predict the forming limit diagrams for sheet metals. Shifting attention to springback, Jung et al. [13] examine the anisotropic springback recovery of advanced high-strength steels using a combined isotropic-kinematic hardening model and applying it to a U-bending process. Seo et al. [14] evaluate the effect of the material models on springback predictions for TRIP 1180 steel. In particular, they use the Hill 1948 and Yld2000-2D yield criteria along with the Yoshida-Uemori kinematic hardening model in finite element simulations of U-bending and T-shape drawing. Trzepiecinski and Lemu [15] examine the effect of anisotropy on the springback predictions for DC04 automotive steel sheets and the impact of the simulation parameters on the accuracy of the predictions. Phanitwong et al. [16] use a combination of finite element analysis and statistical analysis to ascertain the effect of U-bending geometry parameters on springback.

Some of the contributions examine forming limits and defects in the context of actual manufacturing processes. Centeno et al. [17] examine formability and failure in single point incremental forming (SPIF) of AISI304-H111 sheets and compare it to conventional forming conditions, e.g., the Nakajima and stretch-bending tests. Among other things, they determine the conditions upon which necking is suppressed, so that failure in SPIF is by ductile fracture. Abebe et al. [18] examine springback in multi-point dieless forming, especially in the context of reducing computational time. They propose to replace numerical simulations of springback with statistical analyses based on design of experiments.

\section{Closing Remarks}

In the process of creating this Issue, we were fortunate to have the expert assistance of the Beijing office of Metals. To the staff who expertly coordinated the reviews and processing of the papers, we express our sincere thanks. We also express our gratitude to the anonymous reviewers who provided timely and constructive reviews of the submitted manuscripts.

This Special Issue attracted 18 contributions from 12 countries, indicating that advancing research in manufacturing in general, and plastic forming in particular, is a truly global affair. We are looking forward to the research advances in plastic forming in the years to come, and hope that this Special Issue has contributed to a small extent to a greener and more prosperous future for all.

Conflicts of Interest: The authors declare no conflict of interest. 


\section{References}

1. Du, S.; Zan, X.; Li, P.; Luo, L.; Zhu, X.; Wu, Y. Comparison of Hydrostatic Extrusion between Pressure-Load and Displacement-Load Models. Metals 2017, 7, 78. [CrossRef]

2. Amigo, F.J.; Camacho, A.M. Reduction of Induced Central Damage in Cold Extrusion of Dual-Phase Steel DP800 Using Double-Pass Dies. Metals 2017, 7, 335. [CrossRef]

3. Behrens, B.-A.; Chugreev, A.; Awiszus, B.; Graf, M.; Kawalla, R.; Ullmann, M.; Korpala, G.; Wester, H. Sensitivity Analysis of Oxide Scale Influence on General Carbon Steels during Hot Forging. Metals 2018, 8 , 140. [CrossRef]

4. Alexandrov, S.; Šidjanin, L.; Vilotić, D.; Movrin, D.; Lang, L. Generation of a Layer of Severe Plastic Deformation near Friction Surfaces in Upsetting of Steel Specimens. Metals 2018, 8, 71. [CrossRef]

5. Han, Y.; Yan, S.; Sun, Y.; Chen, H. Modeling the Constitutive Relationship of Al-0.62Mg-0.73Si Alloy Based on Artificial Neural Network. Metals 2017, 7, 114. [CrossRef]

6. Zhou, P.; Ma, Q.; Luo, J. Hot Deformation Behavior of As-Cast 30Cr2Ni4MoV Steel Using Processing Maps. Metals 2017, 7, 50. [CrossRef]

7. Zhang, Y.; Jiang, S. The Mechanism of Inhomogeneous Grain Refinement in a NiTiFe Shape Memory Alloy Subjected to Single-Pass Equal-Channel Angular Extrusion. Metals 2017, 7, 400. [CrossRef]

8. Salcedo, D.; Luis, C.J.; Luri, R.; Puertas, I.; León, J.; Fuertes, J.P. Design and Mechanical Properties Analysis of AA5083 Ultrafine Grained Cams. Metals 2017, 7, 116. [CrossRef]

9. Zhao, W.; Huang, S.-J.; Wu, Y.-J.; Kang, C.-W. Particle Size and Particle Percentage Effect of AZ61/SiCp Magnesium Matrix Micro- and Nano-Composites on Their Mechanical Properties Due to Extrusion and Subsequent Annealing. Metals 2017, 7, 293. [CrossRef]

10. Li, R.; Eyckens, P.; E, D.; Gawad, J.; Poucke, M.V.; Cooreman, S.; Bael, A.V. Advanced Plasticity Modeling for Ultra-Low-Cycle-Fatigue Simulation of Steel Pipe. Metals 2017, 7, 140. [CrossRef]

11. Morales-Palma, D.; Martínez-Donaire, A.J.; Vallellano, C. On the Use of Maximum Force Criteria to Predict Localised Necking in Metal Sheets under Stretch-Bending. Metals 2017, 7, 469. [CrossRef]

12. Chalal, H.; Abed-Meraim, F. Numerical Predictions of the Occurrence of Necking in Deep Drawing Processes. Metals 2017, 7, 455. [CrossRef]

13. Jung, J.; Jun, S.; Lee, H.-S.; Kim, B.-M.; Lee, M.-G.; Kim, J.H. Anisotropic Hardening Behaviour and Springback of Advanced High-Strength Steels. Metals 2017, 7, 480. [CrossRef]

14. Seo, K.-Y.; Kim, J.-H.; Lee, H.-S.; Kim, J.H.; Kim, B.-M. Effect of Constitutive Equations on Springback Prediction Accuracy in the TRIP1180 Cold Stamping. Metals 2018, 8, 18. [CrossRef]

15. Trzepiecinski, T.; Lemu, H.G. Effect of Computational Parameters on Springback Prediction by Numerical Simulation. Metals 2017, 7, 380. [CrossRef]

16. Phanitwong, W.; Boochakul, U.; Thipprakmas, S. Design of U-Geometry Parameters Using Statistical Analysis Techniques in the U-Bending Process. Metals 2017, 7, 235. [CrossRef]

17. Centeno, G.; Martínez-Donaire, A.J.; Bagudanch, I.; Morales-Palma, D.; Garcia-Romeu, M.L.; Vallellano, C. Revisiting Formability and Failure of AISI304 Sheets in SPIF: Experimental Approach and Numerical Validation. Metals 2017, 7, 531. [CrossRef]

18. Abebe, M.; Yoon, J.-S.; Kang, B.-S. Radial Basis Functional Model of Multi-Point Dieless Forming Process for Springback Reduction and Compensation. Metals 2017, 7, 528. [CrossRef]

(C) 2018 by the authors. Licensee MDPI, Basel, Switzerland. This article is an open access article distributed under the terms and conditions of the Creative Commons Attribution (CC BY) license (http://creativecommons.org/licenses/by/4.0/). 